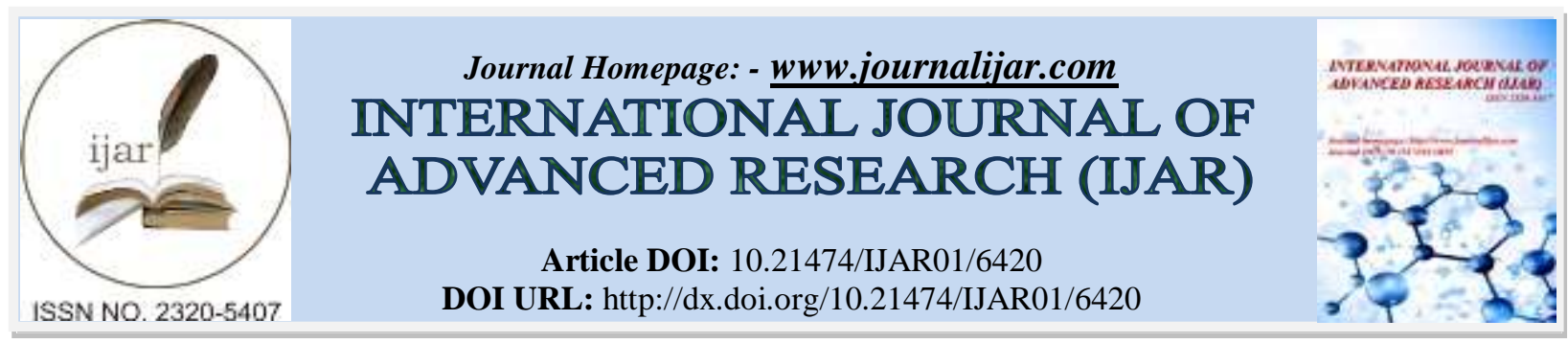

RESEARCH ARTICLE

\title{
SURGICAL SITE INFECTION AMONG GYNAECOLOGICAL AND OBSTETRIC ABDOMINAL SURGERIES.
}

\section{Dr. Janhavi Bhagat ${ }^{1}$ and Dr. Yashwant Kulkarni ${ }^{2}$.}

1. Post Graduate Student, Department of Department of Obstetrics and Gynaecology, Bharati Vidyapeeth Deemed University - Medical College and Hospital, Pune.

2. Assistant Professor, Department of Department of Obstetrics and Gynaecology, Bharati Vidyapeeth Deemed University - Medical College and Hospital, Pune.

\section{Manuscript Info}

[.........................

Manuscript History

Received: 02 December 2017

Final Accepted: 04 January 2018

Published: February 2018

Key words:-

Emergency Surgeries,

Gynaecological Surgeries, Obstetric

Surgeries, Obesity, Surgical Site

Infection.

\section{Abstract}

Introduction: Present study was conducted to find the incidence and risk factors of surgical site infection among gynaecological \& obstetric elective and emergency abdominal surgeries. Materials \& Methods: A hospital based prospective analytical study was conducted at Department of Obstetrics and Gynaecology, Bharati Vidyapeeth University Medical College and Bharati Hospital. A total of 100 females undergoing abdominal surgeries at our hospital were selected for study after informed consent. Patients undergoing surgeries were graded according to ASA score. Operated patients were followed up regularly, during the post-operative period. The wound was classified as per CDC criteria and were checked on $3^{\text {rd }}$ post operatively day routinely and later according to the complaints of the patients. Presence of erythema, pain and discharge were taken as signs of surgical site infection. Wound swab were taken from where the discharge was present and sent for culture and sensitivity. Results: Prevalence of Surgical site infections in present study was $10 \%$. Most common organism isolated from SSI site was Staph. Aureus (4 cases) followed by E.coli ( 2 cases) and Klebsilla (2 cases). Prevalence of SSI was $11.1 \%$ in gynaecological procedures while it was $9.1 \%$ in obstetric procedures ( $\mathrm{p}-0.75)$. A significant association was observed between prevalence of SSI and higher ASA grade, BMI, presence of diabetes and contaminated wounds. Conclusion: The key risk factors for surgical site infection identified in present study were: elevated BMI, poor pre-op health status, diabetes, emergency procedure and contamination of wounds. The multiple risk factors identified in the present study can be helpful for SSI risk stratification and prioritizing interventions in low-middle income countries.

Copy Right, IJAR, 2018,. All rights reserved.

\section{Introduction:-}

Infection in Obstetrics accounts for the second most common cause of maternal mortality next to post-partum hemorrhage. Among surgical patients in obstetrics, surgical site infections (SSIs) are the most common nosocomial infections, accounting for $38 \%$ of hospital acquired infections [1]. According to the Center for Disease Control and

Corresponding Author:- Janhavi Bhagat. 
prevention (CDC) SSIs are classified as being either incisional or organ space that must develop within 30 days of operation. Incisional SSIs are further divided into those involving only skin and subcutaneous tissue (superficial incision SSI) and those involving the deeper soft tissue of the incision (deep incisional SSI). Organ/ space SSIs involve any part of the anatomy (e.g. organ/space) other than incisional body wall layers that was opened or manipulated during an operation [2]. The CDC definitions of SSIs have been applied consistently by surveillance and surgical personnel in many settings and currently are the de facto national standards [3]. Operations in obstetrics involve some degree of bacterial contamination, and are classified as 'clean-contaminated' cases, even when the patient has no preoperative symptoms of active infection.

Surgical wounds are generally classified according to the degree of contamination [4]: Clean: an uninfected operative wound in which no inflammation is encountered and the alimentary, genital or urinary tract is not entered; Clean contaminated: a wound in which the alimentary, genital or urinary tract is entered in a controlled manner; Contaminated: open, new accidental wounds, or operations in which there is a significant break in aseptic technique (e.g. gross contamination with GI tract contents) or acute non-purulent inflammation is encountered; Dirty: old traumatic wounds with devitalised tissue, or those involving existing infection or visceral perforation.

SSI leads not only to substantial morbidity and mortality, but also to longer hospital stays and greater health-care costs [5]. SSI can also influence patient quality of life and work productivity because of time spent in hospital. These infections are usually caused by exogenous and/or endogenous micro-organisms that enter the operative wound either during the surgery (primary infection) or after the surgery (secondary infection).

Primary infections are usually more serious, appearing within five to seven days of surgery [6]. Majority of SSIs are uncomplicated involving only skin and subcutaneous tissue but sometimes can progress to necrotizing infections. The usual presentation of infected surgical wound can be characterized by pain, tenderness, warmth, erythema, swelling and pus formation $[7,8]$.

A number of patient related factors (old age, nutritional status, pre-existing infection, co-morbid illness) and procedure related factors (emergency/ elective, poor surgical technique, prolonged duration of surgery, pre-operative part preparation and inadequate sterilization of surgical instruments) can influence the risk of SSIs significantly [2].

The present research was thus conducted to identify number of cases suffering from surgical site infection (SSI) and to compare the incidence of SSI among elective and emergency obstetrics and gynaecological abdominal surgeries.

\section{Materials and Methods:-}

A hospital based prospective analytical study was conducted at department of Obstetrics and Gynaecology, Bharati Vidyapeeth University Medical College and Bharati Hospital. Consecutive type of non-probability sampling was followed for the selection of study subjects. A total of 100 females undergoing abdominal surgeries at our hospital were selected for study after informed consent.

Patients with SSI occurring within 30 days after operation involving only skin and subcutaneous tissue were included. Patients who are not operated in Bharati hospital or coming with surgical site infection after getting discharge from the hospital were excluded.

A detailed history was taken from all patients followed by through general and systemic examination along with necessary investigation. The patients were prepared for operative procedures through abdominal approach, either elective or emergency as per standard hospital protocol. Patients undergoing surgeries were graded according to ASA score [8]. Operated patients were followed up regularly, during the post-operative period. The wound was classified as per CDC criteria and were checked on $3^{\text {rd }}$ post operatively day routinely and later according to the complaints of the patients.

Presence of erythema, pain and discharge were taken as signs of surgical site infection. Wound swab were taken from where the discharge was present and sent for culture and sensitivity.

\section{Statistical Analysis:-}

The quantitative data was represented as their mean \pm SD. Categorical and nominal data was expressed in percentage. The t-test was used for analysing quantitative data, or else non parametric data was analyzed by Mann 
Whitney test. Categorical data was analyzed by using chi-square test. The significance level of p value was set at $<0.05$. All analysis was carried out by using SPSS software version 21.

\section{Results:-}

Mean age of the study subjects was 38.1 years with over half of them (56\%) were between 21-40 years of age. Out of total 100 cases, $45 \%$ were gynaecological procedures while rests 55 were obstetric cases. Most common obstetric surgery was LSCS (55\%) while most common gynaecological surgery performed was total abdominal hysterectomy $(25 \%)$ cases while TAH BSO was performed in 14\% cases. Exploratory laparotomy and tubal ligation was done in $3 \%$ cases each (Table $\mathbf{1})$.

Prevalence of Surgical site infections in present study was 10\%. Most common organism isolated from SSI site was Staph.Aureus ( 4 cases) followed by E.coli ( 2 cases) and Klebsilla ( 2 cases). Prevalence of SSI was $11.1 \%$ in gynaecological procedures while it was $9.1 \%$ in obstetric procedures (p-0.75) (Table 2).

Prevalence of SSI was significantly higher in cases with emergency procedures as compared to elective procedures (23.1\% vs 5.4\%; $<0.05)$. A significant association was also observed between prevalence of SSI and higher ASA grade (Grade I, II and III: 4.3\%, 23.1\% \& 20\%; p<0.05), high BMI (> $\left.30 \mathrm{Kg} / \mathrm{m}^{2}\right)(42.9 \%$ vs $7.5 \%$; p<0.05) and diabetics $(30 \%$ vs $5.0 \%$; $<<0.05)$. No association was observed between prevalence of SSIs with hypertension ( $\mathrm{p}-$ 0.144 ) and anemia (p-0.308). As per CDC wound criteria, significantly higher prevalence of SSI was seen in contaminated wounds $(36.4 \%)$ as compared to clean \& contaminated (5.3\%) and clean wounds (9.4\%) (Table 3).

No difference was observed between subjects with and without SSIs with respect to mean age, haemoglobin and leucocyte count $(\mathrm{p}>0.05)$. However, mean hospital stay was significantly higher in cases with SSIs (7.6 vs 4.49 days) (Table 4).

\section{Discussion:-}

Very few studies in India, have reported the incidence and risk factors associated with Obstetric and Gynaecological surgeries simultaneously. In present study, the prevalence of surgical site infections among obstetric and gynaecological surgeries was $10 \%$. In a study by Pathak et al. [12], the cumulative incidence rate of SSI was $7.84 \%$ (95\% CI 6.30-9.38) while Shahane V et al. [10] and Nisa MN et al. [14] observed the cumulative incidence as 6\% and $6.5 \%$ respectively.

Various other authors have separately reported incidence of SSIs among obstetric and gynaecological procedures. In present study prevalence of SSIs was $11.1 \%$ in gynaecological procedures while it was $9.1 \%$ in obstetric procedures. Amenu D et al. [9] observed an overall surgical site infection rate of $11.4 \%$ among women having surgery for Obstetric reasons. Devjani et al. [11] observed the incidence as $24.2 \%$ following lower segment caesarean section while in similar studies Ansar A et al. [13] Ghuman et al. [15], Vijayan et al. [16] observed the prevalence as 5.8\%, $5 \%$ and $4.1 \%$ respectively.

Prevalence of SSI was significantly higher in cases with emergency procedures as compared to elective procedures $(23.1 \%$ vs $5.4 \%$; $\mathrm{p}<0.05)$. Various studies have shown that emergency cases land up in SSI more than the elective ones [17-23]. Amenu D et al. [9] in their study observed Surgical Site Infections rate to be two times higher in emergency procedures as compared to that of elective cases. Kishwar $\mathrm{N}$ et al. [18] also observed emergency caesarean sections as risk factor for development of SSI.

We observed a higher prevalence of SSI in contaminated wounds $(36.4 \%)$ as compared to clean \& contaminated $(5.3 \%)$ and clean wounds $(9.4 \%)$. This is an expected observation as it is well known that patients with contaminated wounds have nearly three-fold increased risk of SSI compared to non-contaminated wounds [24,25]. Shahne V et al. [10] in their study observed that rate of infection was highest in contaminated type of wounds (12.3\%), followed by clean contaminated wounds $(8.0 \%)$ and least in clean wounds (4.6\%). In a study by Anvikar et al. [26], similar rates were noted i.e. percentage of infection rate was $10.6 \%$ and $4 \%$ in clean contaminated and clean cases respectively while in Mumbai, Lilani et al. [27], prevalence was $22.4 \%$ and $3.0 \%$ respectively.

The ASA score is a subjective assessment of a patient's overall health that is based on five classes (I to V) with class I being completely healthy fit patient and V was moribund patient. In present study, a significant association was 
observed between higher ASA grade and prevalence of SSI (Grade I, II and III: 4.3\%, 23.1\% \& 20\%; p<0.05). Various studies have shown that ASA score greater than 2 is a risk factor for development of SSIs [28-31]. Morgan et al. [28] in their study observed that ASA score of more than two was associated with increase in risk of SSI by 1.52 times. A study on SSI following cesarean section from Tanzania showed that ASA score more than 3 had about 2.7 times higher risk for SSI [29]. Other studies showed the risk as 1.79 times [30] and 1.61 times [31] respectively.

Certain underlying conditions like diabetes, obesity, anemia and smoking may alter or decrease the immune status thus significantly increasing the risk of SSI. Patients of diabetes especially with poor glycemic control share much comorbidity, like obesity, poor nutritional status, poor peripheral oxygen supply, and metabolic derangements [32]. In present study, Prevalence of SSI was significantly higher in cases with associated co-morbidities like obesity $(42.9 \%$ vs $7.5 \%$; $\mathrm{p}<0.05)$ and diabetes ( $30 \%$ vs $5.0 \%$; $\mathrm{p}<0.05)$. In a study by Ghuman $\mathrm{M}$ et al. [15], key risk factors for surgical site infection post-caesarean section were elevated BMI and diabetes. Vijayan et al. [16] in their study also observed high body mass index (BMI) (above 25) and blood sugar levels as risk factor for SSIs in multivariate analysis. Noveli $\mathrm{S}$ et al. [17] observed poor nutrition and diabetes as the common risk factors in obese women at risk of development of SSIs after CS.

Most common organism isolated from SSI site was Staph.Aureus (4 cases) followed by E.coli (2 cases) and Klebsilla ( 2 cases) while 1 cases yielded no growth. In a study by Nisa MN et al. [14], the commonest organism isolated was Staphylococcus aureus followed by E.coli. In various other studies as well, Staphylococcus aureus has dominated the scene in cases with SSIs [27,33-35]. However, Shahane V et al. [10] in their study observed that out of 18 SSI cases, E.coli was the most common organism followed by Staph. Aureus. In the study by Devjani et al. [11], commonest isolate was Acinetobacter species (32.03\%) followed by Staphylococcus aureus and coagulase negative Staphylococcus (21.09\%).

\section{Conclusion:-}

The incidence of SSI was same for Obstetric as well as Gynaecological surgeries. The key risk factors for surgical site infection identified in present study were: elevated BMI, poor pre-op health status, diabetes, emergency procedure and contamination of wounds. The multiple risk factors identified in the present study can be helpful for SSI risk stratification and prioritizing interventions in low-middle income countries.

Table 1:- Distribution of patients according to type of surgery

\begin{tabular}{|l|l|l|}
\hline Type of Surgery & $\mathbf{N}$ & $\mathbf{\%}$ \\
\hline LSCS & 55 & $55.00 \%$ \\
\hline TAH & 25 & $25.00 \%$ \\
\hline TAH with BSO & 14 & $14.00 \%$ \\
\hline Exploratory Laparotomy & 3 & $3.00 \%$ \\
\hline Tubal Ligation & 3 & $3.00 \%$ \\
\hline Total & 100 & $100.00 \%$ \\
\hline
\end{tabular}

Table 2:- Association of type of procedure with development of SSIs

\begin{tabular}{|l|l|l|l|}
\hline \multirow{2}{*}{ Procedure } & SSI & \multirow{2}{*}{ Total } \\
\cline { 2 - 4 } & No & Yes & \\
\hline \multirow{2}{*}{ Obstetric } & 40 & 5 & 45 \\
\cline { 2 - 4 } & $88.90 \%$ & $11.10 \%$ & $100.00 \%$ \\
\hline \multirow{2}{*}{ Total } & 50 & 5 & 55 \\
\cline { 2 - 4 } & $90.90 \%$ & $9.10 \%$ & $100.00 \%$ \\
\hline \multirow{2}{*}{ p- value $-\mathbf{0 . 7 5}$} & 90 & 10 & 100 \\
\cline { 2 - 4 } & $90.00 \%$ & $10.00 \%$ & \\
\hline
\end{tabular}

Table 3:- Association of various factors with development of SSIs

\begin{tabular}{|l|l|l|l|l|}
\hline \multirow{2}{*}{ Type of Procedure } & SSI & Tes (n-10) & & \multirow{2}{*}{ p-value } \\
\cline { 2 - 4 } & No $(\mathbf{n}-\mathbf{9 0})$ & 6 & 26 & \\
\hline \multirow{2}{*}{ Emergency } & 20 & $23.08 \%$ & $100.00 \%$ & \\
\cline { 2 - 4 } & $76.92 \%$ & $\mathbf{0 . 0 5}$ & \\
\hline
\end{tabular}




\begin{tabular}{|c|c|c|c|c|}
\hline \multirow{2}{*}{ ASA Grade II/ III } & 24 & 7 & 31 & \multirow[t]{2}{*}{$<0.05$} \\
\hline & $77.42 \%$ & $22.58 \%$ & $100.00 \%$ & \\
\hline \multirow[t]{2}{*}{ Obesity } & 4 & 3 & 7 & \multirow[t]{2}{*}{$<0.05$} \\
\hline & $57.14 \%$ & $42.86 \%$ & $100.00 \%$ & \\
\hline \multirow[t]{2}{*}{ Diabetes } & 14 & 6 & 20 & \multirow[t]{2}{*}{$<0.05$} \\
\hline & $70.00 \%$ & $30.00 \%$ & $100.00 \%$ & \\
\hline \multirow[t]{2}{*}{ Hypertension } & 11 & 3 & 14 & \multirow[t]{2}{*}{0.144} \\
\hline & $78.57 \%$ & $21.43 \%$ & $100.00 \%$ & \\
\hline \multirow[t]{2}{*}{ Anemia } & 53 & 8 & 61 & \multirow[t]{2}{*}{0.308} \\
\hline & $86.89 \%$ & $13.11 \%$ & $100.00 \%$ & \\
\hline \multirow{2}{*}{$\begin{array}{l}\text { Contaminated } \\
\text { Wound }\end{array}$} & 7 & 4 & 11 & \multirow[t]{2}{*}{$<0.05$} \\
\hline & $63.64 \%$ & $36.36 \%$ & $100.00 \%$ & \\
\hline
\end{tabular}

Table 4:- Mean comparison of variables with development of SSIs

\begin{tabular}{|l|l|l|l|l|l|}
\hline Variables & SSI & N & Mean & SD & p- value \\
\hline \multirow{2}{*}{ Age (years) } & No & 90 & 37.81 & 12.96 & \multirow{0}{*}{$\mathbf{0 . 3 9}$} \\
\cline { 2 - 5 } & Yes & 10 & 41.5 & 14 & \\
\hline \multirow{2}{*}{ Hemoglobin (gm\%) } & No & 90 & 9.43 & 1.44 & \multirow{2}{*}{$\mathbf{0 . 0 6 1}$} \\
\cline { 2 - 5 } & Yes & 10 & 8.55 & 0.89 & \\
\hline \multirow{2}{*}{ HLC (/cu mm) } & No & 90 & 11197.78 & 3131.54 & \multirow{2}{*}{$\mathbf{0 . 5 4 6}$} \\
\cline { 2 - 5 } & Yes & 10 & 10550.04 & 3858.97 & \\
\cline { 2 - 5 } & No & 90 & 4.49 & 1.6 & \\
\cline { 2 - 4 } & Yes & 10 & 7.6 & 2.99 & \\
\hline
\end{tabular}

\section{References:-}

1. Morgan AJ, Horan TC, Pearson ML, Silver LC, Jarvis WR. The hospital infection control practices Advisory Committee: A guideline for prevention of surgical site infection. Infect control and hospital epidemiol. 1999;20(4):247-278.

2. Horan TC, Gaynes RP, Martone WJ, Tarvis WR, Emori TG. CDC definition of nosocomial surgical site infection: a modification of CDC definition of surgical wound infection. Infect control and hospital epidemiol. 1992;13(10):606-608.

3. Taylor G, Mckenzie M, Kirkland T, Wiens R. Effect of surgeon's diagnosis on surgical wound infection rates. Am J infect control. 1990;18(5):295-299.Mangram AJ, Horan TC, Pearson ML, Silver LC, Jarvis WR. Guideline for prevention of surgical site infection, 1999. Hospital Infection Control Practices Advisory Committee. Infection Control and Hospital Epidemiology April 1999;20(4):250-78.

4. Mangram AJ, Horan TC, Pearson ML, Silver LC, Jarvis WR. Guideline for prevention of surgical site infection, 1999. Hospital Infection Control Practices Advisory Committee. Infection Control and Hospital Epidemiology April 1999;20(4):250-78.

5. Kirkland KB, Briggs JP, Trivette SL, Wilkinson WE, Sexton DJ. The impact of surgical-site infections in the 1990s: attributable mortality, excess length of hospitalization, and extra costs. Infect Control Hosp Epidemiol 1999;20:725.

6. Pradhan GB, Agrawal J. Comparative study of post operative wound infection following emergency lower segment caesarean section with and without the topical use offusidic acid. Nepal Med Coll J. 2009;11(3):18991.

7. Ahmed MI. Prevalence of nosocomial wound infection among postoperative patients and antibiotics patterns at teaching hospital in Sudan. N Am J Med Sci. 2012;4(1):29-34.

8. Mulu W, Kibru G, Beyene G, Datie M. Postoperative nosocomial infections and antimicrobial resistance patterns of bacterial isolates among patients admitted at FelegeHiwot Referral Hospital, Bahirdar, Ethiopia. Ethiop J Health Sci. 2012;22(1):7-18.

9. Amenu D, Belachew T, Araya F. Surgical site infection rate and risk factors among obstetric cases of Jimma University Specialized Hospital, Southwest Ethiopia. Ethiopian journal of health sciences. 2011;21(2):91-100.

10. Shahane V, Bhawal S, Lele MU. Surgical site infections: A one year prospective study in a tertiary care center. International journal of health sciences. 2012 Jan;6(1):79. 
11. Devjani D, Saxena S, Mehta G, Yadav R, Dutta R. Risk factor analysis and microbial etiology of surgical site infections following lower segment caesarean section. International Journal of Antibiotics. 2013 Sep 1;2013.

12. Pathak A, Mahadik K, Swami MB, Roy PK, Sharma M, Mahadik VK, Lundborg CS. Incidence and risk factors for surgical site infections in obstetric and gynecological surgeries from a teaching hospital in rural India. Antimicrobial Resistance \& Infection Control. 2017 Jun 14;6(1):66.

13. Ansar A. Surgical site infection in obstetrics practice. Pak J Surg. 2013 Apr;18:2.

14. Nisa, M., Naz, T., Afzal, I., Hassan, L. Scope of Surgical Site Infection (Ssi) in Obstetrics And Gynaecology. Journal of Postgraduate Medical Institute (Peshawar - Pakistan), North America, 19. 2011.

15. Ghuman M, Rohlandt D, Joshy G, Lawrenson R. Post-caesarean section surgical site infection: rate and risk factors. The New Zealand Medical Journal (Online). 2011 Jul 29;124(1339).

16. Vijayan CP, Mohandas S, Nath AG. Surgical Site Infection Following Cesarean Section in a Teaching Hospital. International Journal of Scientific Study. 2016; 3(12): 97-104.

17. Novelia S, Sia WS, Songwathana P. Surgical Site Infection among Women Post Cesarean Section: An Integrative Review. Nurse Media Journal of Nursing. 2017 Jul 5;7(1):46-55.

18. Kishwar N, Hayat N, Ayoub S, Ali S. Surgical site infections among patients undergoing elective versus emergency caesarean section. Journal of Postgraduate Medical Institute (Peshawar-Pakistan). 2016 Nov 26;30(4).

19. Mahesh CB, Shivakumar S, Suresh BS, Chidanand SP, Vishwanath Y. A prospective study of surgical site infections in a teaching hospital. J Clin Diagn Res 2010;4:3114-9.

20. Berard F, Gandon J. Factors influencing the incidence of wound infection. Ann Surg. 1964;160:32-81.

21. Cruse PJE. Surgical wound infection. In: Gorbach SL, Bartlett JG, Blacklow NR, editors. Infectious diseases. W.B. Saunders Company, Harcourt Brace Jovanovich Inc; Philadephia. London, Toronto, Montreal, Sydney. Tokyo: 1992. pp. 738-64.

22. Beck WC, Deshmukh N. Surgical infections. In: Groschel D, editor. Handbook on Hospital Associated Infections in the General Hospital population and specific measures of control. Marcel Dekker, Inc; New York, Basel: 1979. pp. 1-24.

23. Cruse PJE, Ford R. A five year prospective study of 23,649 surgical wounds. Arch Surg. 1973;107:206-9.

24. World Health Organization. Global guidelines on the prevention of surgical site infection. 2106.

25. Culver DH, Horan TC, Gaynes RP, Martone WJ, Jarvis WR, Emori TG, Banerjee SN, Edwards JR, Tolson JS, Henderson TS, et al. Surgical wound-infection rates by wound class, operative procedure, and patient risk index. Am J Med. 1991;91:S152-S157. doi: 10.1016/0002-9343(91)90361-Z.

26. Anvikar AR, Deshmukh AB, Karyakarte RP, Damle AS, Patwardhan NS, Malik AK, et al. A one year prospective study of 3280 surgical wounds. Indian J Medical Microbiol. 1999;17(3):129-32.

27. Lilani SP, Jangale N, Chowdhary A, Daver GB. Surgical site infection in clean and clean-contaminated cases. Indian J Medical Microbiol. 2005;23(4):249-52.

28. Morgan DM, Swenson CW, Streifel KM, Kamdar NS, Uppal S, Burgunder-Zdravkovski L, Pearlman MD, Fenner DE, Campbell DA. Surgical site infection following hysterectomy: adjusted rankings in a regional collaborative. Am J Obstet Gynecol.

29. Mpogoro FJ, Mshana SE, Mirambo MM, Kidenya BR, Gumodoka B, Imirzalioglu C. Incidence and predictors of surgical site infections following caesarean sections at Bugando medical Centre, Mwanza, Tanzania. Antimicrob Resist Infect Control.

30. Lake AG, McPencow AM, Dick-Biascoechea MA, Martin DK, Erekson EA. Surgical site infection after hysterectomy. Am J Obstet Gynecol. 2013;209(5):490 e491-490 e499.

31. Shree R, Park SY, Beigi RH, Dunn SL, Krans EE. Surgical site infection following cesarean delivery: patient, provider, and procedure-specific risk factors. Am J Perinatol. 2016;33(2):157-164.

32. Berard F, Gandon J. Factors influencing the incidence of wound infection. Ann Surg. 1964;160:32-81.

33. Khan MA, Ansari MN, Bano S. Post operative wound infection. Ind. J. Surg. 1985;48:383-86.

34. Rao AS, Harsha M. Postoperative wound infections. J. Indian M.A. 1975;64(4):90-3.

35. Prabhakar H, Arora S. A bacteriological study of wound infections. J Indian Med Assoc. 1979;73(9\&10):1458. 